\title{
Suicide among LGBTQIA + youth: A review of the treatment literature
}

\author{
Jody Russon $^{\mathrm{a},{ }^{*}, \text { Regina Washington }}{ }^{\mathrm{b}}$, Ana Machado ${ }^{\mathrm{c}}$, Lauren Smithee ${ }^{\mathrm{a}}$, Jamie Dellinger ${ }^{\mathrm{a}}$ \\ ${ }^{\text {a } V i r g i n i a ~ P o l y t e c h n i c ~ I n s t i t u t e ~ a n d ~ S t a t e ~ U n i v e r s i t y, ~ U S A ~}$ \\ ${ }^{\mathrm{b}}$ International Association of Providers of AIDS Care, USA

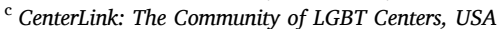

\section{A R T I C L E I N F O}

\section{Keywords:}

Suicide treatment

LGBTQIA+ populations

Adolescents and young adults

\begin{abstract}
A B S T R A C T
Suicide is a serious public health problem among adolescent and young adults. Indeed, 12.1\% of adolescents contemplate suicide, $4.0 \%$ make a plan, and 4.1\% make an attempt (Nock et al., 2013). LGBTQIA+ youth (i.e., lesbian, gay, bisexual, transgender, questioning/queer, intersex and/or asexual adolescents and young adults) are particularly vulnerable to suicide (CDC, 2016; Liu \& Mustanksi, 2012; Peters et al., 2019). While many LGBTQIA + youth are healthy and resilient (Ream \& Savin-Williams, 2005) they often report higher rates of both suicidal ideation and behavior than their heterosexual (Haas et al., 2011) and cisgender (James et al., 2016) peers. The purpose of this paper is to provide a structured review the state of suicide treatment research for LGBTQIA+ youth and offer recommendations for future directions.
\end{abstract}

\section{Introduction}

Suicidality among adolescent and young adult populations continues to be a serious public health concern (Nock et al., 2013). LGBTQIA+ youth (i.e., lesbian, gay, bisexual, transgender, questioning/queer, intersex and/or asexual adolescents and young adults) are particularly vulnerable to suicide (CDC, 2016; Liu \& Mustanksi, 2012; Peters et al., 2019). LGBTQIA + youth are up to 5-8 times more likely to experience suicidal ideation than their heterosexual and cisgender counterparts (Almeida et al., 2009; Taliaferro \& Muehlenkamp, 2017; Toomey et al., 2018). In fact, suicide is the third leading cause of death for youth ages 15-19 years old (World Health Organization, 2019). 19 years old LGBTQIA+ youth are overrepresented in these statistics. Lesbian, gay, and bisexual youth are three times more likely than heterosexual youth to attempt suicide, and $41 \%$ of transgender people have attempted suicide during their lifetime. While many LGBTQIA+ youth are healthy and resilient (Ream \& Savin-Williams, 2005) they often report higher rates of both suicidal ideation and behavior than their heterosexual (Haas et al., 2011) and cisgender (James et al., 2016) peers. Consequently, specific interventions targeting suicide among LGBTQIA+ populations are critical.

The purpose of this paper is to provide a structured review the state of suicide treatment research for LGBTQIA + youth and offer recommendations for future directions. We first, however, provide background about LGBTQIA + identities and how these populations have been involved in research efforts. This introduction will focus on sex, gender and sexual orientation separately; however, it is important to note that intersectionality exists between these identities (e.g., gay, transgender men; and bisexual, intersex, non-binary people). We also acknowledge that many more identities are represented in the LGBTQIA+ acronym that are not discussed explicitly here (e.g., agender, non-binary) as they are, unfortunately, underrepresented in the literature. We recommend future research efforts seek to be inclusive of these identities.

\subsection{Sex, sexual orientation, and gender identity}

Historically, LGBTQIA+ individuals have not been well represented in the suicide literature. Although recently, more attention has been focused on these populations, researchers are only just beginning to attend to the unique characteristics of LGBTQIA+ youth. To increase involvement of these youth in clinical practice and clinical trials, providers and researchers must become more culturally educated about the unique challenges of working with this population. There is extensive literature that can help professionals acquire this knowledge. This includes the American Psychological Association's (2015) Guidelines for Psychological Practice with Transgender and Gender Nonconforming People, the World Professional Association for Transgender Health's (2018) WPATH Standards of Care, Family Acceptance Project (2020),

\footnotetext{
* Corresponding author at: Department of Human Development and Family Sciences, Family Therapy Center of Virginia Tech (0515), 840 University City Boulevard, Suite 1, Blacksburg, VA 24060, USA.

E-mail address: Jrusson@vt.edu (J. Russon).
} 
and Harvey and Stone Fish's (2015) suggestions for working with queer youth in family therapy. Below, we cover several topics that we think would be helpful for researchers to know to engage this population in suicide treatment and clinical research programs.

First, investigators have historically lumped together LGBTQIA+ populations as if they were one, generalized group. That is, studies have not been designed to differentiate suicide rates, risks, and resiliencies associated with each identity within the LGBTQIA+ "umbrella" acronym. Although this "umbrella" term has served the purpose of promoting inclusivity among sexual minorities (e.g., LGBQ), gender minorities (e.g., transgender and gender diverse individuals) and intersex people (Shankle, 2013), LGBTQIA+ identities are not homogenous. The acronym encompasses substantial diversity in sexual orientation (e.g., gay), gender identity (e.g., transgender), gender expression (e.g. feminine presentation) and sex (e.g., intersex). Further, language to describe identities within LGBTQIA+ communities varies. For example, 'intersex' is a term used in scientific communities to describe a person that does not fit the male-female binary, based on their anatomy and/or genetics. This term may not necessarily be used by LGBTQIA+ populations to describe themselves or others. Given this diversity, it is important to differentiate between sex, gender identity, and sexual orientation to understand suicidality and the best courses of treatment. We provide a brief overview below.

Researchers need to understand the difference between sexual orientation and gender identity. Sexual orientation is distinct from one's sex assigned at birth. Sexual orientation is a component of identity that describes a person's physical, emotional, and/or romantic attraction to another person as well as social affiliations associated with this identity (APA, 2012). Sex does not determine a person's attractions, or lackthere-of, and sexual orientation development is not implied by one's features at birth. While sexual orientation describes whom one is attracted to, gender identity is centered on a person's self-concept. Like one's sexual orientation, this sense of self may or may not correspond with sex assigned at birth. Indeed, gender identity is a person's sense of being a woman/girl, man/boy, or an alternative gender (e.g., transgender, genderqueer, non-binary) (PFLAG, 2019). Gender expression is the manifestation of one's gender identity. It is presented in a variety of ways (e.g., voice, dress, behavior, etc.) that may or may not correspond to characteristics associated with femininity or masculinity. Transgender and gender divers (TGD) is a broad term for those whose gender identity is different from expectations based on sex assigned at birth. TGD terminology also includes those who do not identify themselves on the gender binary (e.g., women/girls or men/boys) and instead have aspects of both or neither (e.g., genderqueer, agender, gender fluid) (Singh \& Dickey, 2017).

Finally, the ideology of binarism also constrains our understanding of subtleties in experiences within this population. A societal challenge to understanding uniqueness in LGBTQIA+ identities stems from gender binarism. Gender binarism reinforces the idea that gender can be classified as only two separate forms: male or female (Butler, 1990; Farmer \& Byrd, 2015; Preves, 2000). This belief reinforces "either-or" assumptions about sex, gender, and sexual orientation (Blumer et al., 2013). A binary perspective assumes that one's sex assigned at birth (e.g., biological/ physiological features) dictates gender identity, sexual orientation and self-expression. For example, if one is born with male genitalia, binary cultural expectations assume this person will identify as a man (i.e., cisgender identity), be attracted to women (i.e., straight sexual orientation), and self-express in masculine ways. Under a binary perspective, it is also assumed that a person's sex is the same as their gender, which, in turn, implies corresponding masculine or feminine self-expression (Smith et al., 2012; Wilchins, 2004). In reality, sex, gender identity, and sexual orientation are all distinctive, yet multifaceted attributes of identity (Mizock \& Lundquist, 2016). In addition to reducing nuances in identities among LGBTQIA+ people, binarism can isolate individuals within LGBTQIA + communities that do not have a binary experience with their sex, gender identity, and/or sexual orientation, and can render their experiences invisible.

\section{Framing the treatment review}

To frame the treatment literature in this review, we will discuss three topics. First, we will present two theories that help describe the disproportionate rates of suicide among LGBTQIA+ youth. Next, using these theories, we will discuss the research on differences in suicide risk for these populations noting, where possible, the unique factors that impact LGBQ, TGD, and intersex youth differently. Finally, building on prior information described in theory and differential risk sections, current literature on the most well-researched risk and protective factors for LGBTQIA + youth are described. This information is then synthesized to frame the suicide treatment review for LGBTQIA+ youth.

\subsection{Theory}

Interpersonal theory of suicide and minority stress theory help us understand why LGBTQIA + youth may be vulnerable to suicidal ideation and behavior. We argue below that the minority stressors (i.e., proximal and distal stressors) unique to LGBTQIA + youth make them vulnerable to experiencing two IPTS (Interpersonal Theory of Suicide) interpersonal experiences: thwarted belongingness and perceived burdensomeness. We introduce each theory and describe how they explain disproportionate rates of suicidality among LGBTQIA + youth.

The interpersonal theory of suicide (IPTS; Joiner, 2005; Van Orden et al., 2010) describes how thwarted belongingness and perceived burdensomeness contribute to hopelessness and suicidal desire. IPTS posits that habituation to painful or provocative experiences increases a person's acquired capability to move from suicidal ideation to attempting suicide (Cheek et al., 2016; Chu et al., 2017; Mandracchia \& Smith, 2015). Due to ongoing experiences of stigma and marginalization, LGBTQIA + youth may be particularly susceptible to repeatedly experiencing thwarted belongingness and perceived burdensomeness. The first component of IPTS, perceived burdensomeness, occurs when an individual believes they are a liability and/or burden to others due to their own perceived incompetence (Joiner, 2005; Mandracchia \& Smith, 2015). Perceived burdensomeness captures experiences of social disconnection, and particularly the incorrect assumption that one's life does not have worth (Van Orden et al., 2010). The second component, thwarted belongingness, occurs when one's basic need for affiliation is not met and they do not experience reciprocal care or support in relationships (Joiner, 2005; Mandracchia \& Smith, 2015). The dimensions of thwarted belongingness include loneliness and the absence of feeling cared for in close relationships (Van Orden et al., 2010).

Minority stress theory (MST; Meyer, 2003) explains how unique stressors affect LGBTQIA + youth. MST posits that disparities in mental health and suicide are socially produced through (a) distal (e.g., external) stressors within the environment (e.g., discrimination, marginalization), (b) proximal stressors that reflect internalization of discriminatory cultural attitudes (e.g., internalized homophobia), and (c) interactive proximal stressors that shape ones expectations (e.g., expecting to be rejected as a result of outness). These challenges are exacerbated during adolescence for LGBTQIA+ youth. During adolescence, LGBTQIA + youth begin to solidify their sexual orientation and gender identity. Their increasing awareness of distal stressors in their homes (e.g., caregivers with rejecting behaviors), schools (e.g. victimization), communities (e.g., discrimination), and society (e.g., systemic oppression) may lead to increased levels of internalized stigma (i.e., proximal stressors) and distress (Yüksel et al., 2017). For some TGD youth, the onset of puberty can also cause stress. During adolescence, secondary sex characteristics develop, potentially exacerbating both gender dysphoria and psychological distress for some TGD youth (Drescher \& Byne, 2012; Littman, 2018; Steensma et al., 2011). These factors contribute to LGBTQIA+ youths' perceptions and expectations about how their families and others in their social networks/ 
communities will respond to their sexuality and gender identity, with regard to rejecting behaviors (i.e., interactive proximal stressors). Youth often expect to be admonished for the expression of their gender, rejected, or dismissed by others, contributing to the likelihood of thwarted belongingness (i.e., lack of connection or affiliation). Indeed, it is well-documented that LGBTQIA + youth may have difficulty vocalizing their distress. Specifically, many of these youth feel as though others will not believe them if they feel distressed (e.g., think they are attention-seeking) (McDermott et al., 2018). Without supportive resources and networks, LGBTQIA + youth may be left managing stressors (e.g., homophobic and transphobic discourses, familial and social rejection, bullying and victimization, and/or gender dysphoria) on their own. For many youth, these stressors constitute ongoing, provocative experiences that increase risk for suicide attempts.

There is some research to support how MST and IPTS apply to LGBTQIA+ youth. When used as a framework for research, minority stress theory has been used to describe the unique proximal and distal stressors experienced by LGBTQIA + youth (Frost et al., 2015; Tebbe \& Moradi, 2016), and how these stressors increase suicide risk (Hendricks \& Testa, 2012; Valentine \& Shipherd, 2018). In fact, these minority stressors have been found to mediate the relationship between marginalized LGBTQIA+ identities and negative mental health outcomes, at large (Meyer, 2003; Pitonák, 2017). Further, research consistently demonstrates the higher rates of social exclusion, rejection, and discrimination experienced by this population, compared to heterosexual and cisgender youth (DeCamp \& Bakken, 2016; Meyer et al., 2015; Muehlenkamp et al., 2015; Pitoňák, 2017). Ubiquitous instances of devaluation often contribute to psychological and emotional difficulties, including shame about one's expression (DeCamp \& Bakken, 2016; Meyer, 2003; Pitoňák, 2017). Consequently, LGBTQIA+ youth are more likely than their cisgender and heterosexual peers to experience shame, anxiety, depression, feelings of isolation, and lower self-esteem (Almeida et al., 2009; DeCamp \& Bakken, 2016; McDermott et al., 2018; Pitoňák, 2017).

IPTS has been extensively researched (see Chu et al., 2017 for a review) and applied to LGBQ (Cramer et al., 2014; Hill et al., 2017; Hill \& Pettit, 2012) and TGD youth (Grossman et al., 2016; Testa et al., 2017). When IPTS was applied in a study with TGD youth (Grossman et al., 2016), as predicted, the core tenants of the model were linked to suicidal ideation and/or suicide attempts. It was also found that both transgender girls (assigned male at birth) and transgender boys (assigned female at birth) reported higher percentages of suicidal ideation compared to cisgender, heterosexual youth, while "female-to-differentgender" and "male-to-different-gender" youth reported higher percentages of attempts (Grossman et al., 2016). Results from this sample also indicated that experiences of harmful events and acquired capability were associated with attempts. Not surprisingly, social support has been identified as a factor associated with thwarted belongingness among LGBTQIA+ communities. In a recent study with lesbian, gay, and bisexual young adults, Hill et al. (2017) found that family and lesbian, gay, and bisexual community support were associated with lower thwarted belongingness among, above and beyond depression and demographic factors. In this study, these modes of support were associated with suicide through thwarted belongingness.

Two recent studies on LGB youth have demonstrated evidence for overlap between IPTS and MST. Baams et al. (2015) studied the association between perceived burdensomeness and thwarted belongingness (IPTS model) and sexual minority stressors (MST), finding that IPTS and MST factors were related. For gay and bisexual male youth, perceived burdensomeness mediated the relationship between victimization and depression, while perceived burdensomeness mediated the relationship between victimization and coming out stress for both lesbian and bisexual female youth (Baams et al., 2015). Plöderl et al. (2014) also examined IPTS factors (acquired capability, thwarted belongingness, and perceived burdensomeness) and MST factors (victimization, outness, internalized homophobia) and found that internalized homophobia, outness, and all three IPTS factors were significantly related to suicidal ideation. While these two studies pertain to sexual minority youth only, they provide support for the interconnections between IPTS and MST factors. While more research on IPTS, MST, and suicide in the LGBTQIA + community is needed, this research provides some evidence for using minority stress and IPTS to explain disproportionate rates of suicidal ideation and behavior among LGBTQIA+ youth. It also provides directions for intervening in the interpersonal mechanisms contributing to suicidality among this population.

\subsection{Differential suicide risk among LGBTQIA+ populations}

To further frame this suicide treatment review, this section reviews the literature on subgroup differences among LGBTQIA+ youth. Although sex, gender, and sexual orientation often remain undifferentiated or incompletely reported in suicide research, there is evidence of unique group differences. We will describe differences in suicide risk among the subpopulations under the LGBTQIA + umbrella.

Substantial research exists indicating sex differences in suicide rates (e.g., Boeninger et al., 2010; Nowotny et al., 2015; Park, 2015). In a recent Australian survey, a sample of 176 intersex-identified participants, over half the sample (60\%) had thought about suicide and almost a fifth had attempted suicide (Jones, 2016). The dearth of literature for intersex populations is particularly problematic given that they may be among the most in need of support (McDermott \& Roen, 2012). Differences in suicide rates among cisgender identities (i.e., men, women, boys and girls without trans experience) have been widely studied (see Miranda-Mendizabal et al., 2019 for a systematic review). Until recently, however, transgender and gender diverse (TGD) youth have been absent from suicide research; yet, they are at even greater risk for suicidal behavior than their LGBQ counterparts (Grossman \& D'Augelli, 2007; Peterson et al., 2017). Results from a representative, populationbased sample of high school students confirmed that TGD high school students were nearly twice as likely to experience suicidality compared to cisgender youth (Perez-Brumer et al., 2017). Similarly, Ream (2019) found that transgender youth were most likely to experience suicide attempts compared to both cisgender heterosexual, and both cisgender and lesbian, gay, bisexual, or queer youth. In fact, it is estimated that between 30 and $50 \%$ of TGD youth attempt suicide during their adolescence (Toomey et al., 2018). Research on differences in rates of suicidal thoughts and behaviors between transgender and cisgender adolescents has shown that transgender men and non-binary adolescents (assigned female at birth) report the highest rates of passive ideation, suicide plans, and attempts compared with cisgender youth, transgender women, and non-binary adolescents (assigned male at birth; Thoma et al., 2019; Toomey et al., 2018).

Based on these findings, it is important to consider that a person's gender identity may not be the most accurate measure when assessing their risk. There could be a variety of reasons for why transgender adults and non-binary adolescents who were assigned female at birth would be at the greatest risk of suicidality among other TGD people. One possible explanation is that masculine-appearing adults and teenagers are held to different societal standards regarding self-expression and role embodiment (Moss-Racusin et al., 2010). Therefore, transgender men and boys, who were previously given social permission to express themselves in ways traditionally considered feminine, might experience greater backlash when behaving in ways that were previous acceptable. However, research has found that transgender men reported a significantly higher quality of life when they received affirming hormone therapy than when they did not (Newfield et al., 2006), as well as greater wellbeing when their voices sounded more masculine (Watt et al., 2018). These findings indicate that - for those who are affirmed by appearing more masculine than before - being perceived as more masculine or androgynous could also lead to positive and affirming interactional changes for transgender and non-binary people who were assigned female at birth. 
Among lesbian, gay and bisexual people, bisexual youth may be particularly vulnerable to suicide (Pompili et al., 2014; Y1ldiz, 2018). Bisexual youth, followed by lesbian and gay youth, are more likely to exhibit suicidal behavior (Toomey et al., 2018) than their peers. Although LGBQ youth, at large, are more likely to report repetitive, nonsuicidal self-injury and suicidality compared heterosexual youth, this may be particularly true for bisexual youth (Taliaferro \& Muehlenkamp, 2017). In a study examining mental health symptoms in a large primary care sample of adolescents and young adults (Shearer et al., 2016), lesbians, bisexual females, and questioning females endorsed higher suicide scores across their lifetime than their heterosexual female counterparts. Bisexual females endorsed highest levels current suicidality at the time of assessment. The same may be true for pansexual youth. Recently suicide literature on pansexual individuals, or those who are attracted a person regardless of their sex, gender or physiology, has emerged. In a sample of college students, Horwitz et al. (2020) found that pansexual students had 33\% greater odds of endorsing two or more suicide risk factors than their bisexual counterparts.

\subsection{Risk and protective factors}

Research has revealed several risk and protective factors that correspond with MST and IPTS to help explain why LGBTQIA+ youth are more vulnerable to suicide than their heterosexual and cisgender peers. For a comprehensive review of risk and protective factors for this population, please see Aranmolate et al., 2017; Hall, 2018. Suicidality has been clearly linked to minority stressors for these populations. Such stressors include gender dysphoria, family rejection, identity-based victimization, bullying, stigma, discrimination, and abuse (Aitken et al., 2016; Goldblum et al., 2012; Grossman et al., 2016; Matarazzo et al., 2014; Petersen et al., 2017; Testa et al., 2017; Staples et al., 2017; Yildiz, 2018). There are also multiple protective factors that inhibit the internalization of these stressors. These factors include self-acceptance and self-esteem (Sharaf et al., 2009), as well as social support and connection, namely from one's family, community, peers, and social networks (Kleiman \& Liub, 2013; Sharaf et al., 2009). The literature on the most prominent factors associated with MST and IPTS are reviewed.

\subsubsection{School experiences, bullying and peer victimization}

Bullying and peer victimization are among the strongest predictors of suicide for sexual and gender minority youth. These populations are often more likely to experience bullying and discrimination from their peers compared to cisgender and heterosexual youth (Hatchel et al., 2019; Matarazzo et al., 2014; Y1ld1z, 2018). In a study with sexual and gender minority high school students, Hatchel et al. (2019) found that peer victimization was associated with suicidality and undermined school belongingness and self-compassion. This same research group also found that one third of TGD youth experienced victimization and almost half of TGD youth reported depressive symptoms and suicidal ideation (Hatchel et al., 2018). Cyberbullying has also been associated with suicidality. One literature review on cyberbullying, suicide risk, and within-group differences in sexual and gender minorities found that cyberbullying affected up to half of the sexual and gender minority youth and was one of the strongest predictors of suicide attempts (Abreu \& Kenny, 2017). In Abreu and Kenny's study (2017), bisexual (cisgender) girls and transgender youth were most likely to report having experienced cyberbullying, while gay boys were most likely to experience face-to-face bullying. Suicide attempts were highest among sexual and gender minority youth who had been cyberbullied compared to those youth who had experienced face-to-face bullying (Abreu \& Kenny, 2017). These results indicate that cyberbullying may be more detrimental to some sexual and gender minority youth than face-to-face aggression. Sticca and Perren (2012) suggest that the potential for publicity and anonymity inherent in cyber platforms may make this type of aggression more public and pervasive, and more likely to cause more intense distress among victims. In other words, those engaging in cyberbullying can remain anonymous to their victims while, at the same time, their aggression can be observed by large groups of other online users. Given that LGBTQIA + youth may experience more severe forms of bullying and victimization than their heterosexual and cisgender peers, these factors may be even more pronounced.

Stigma is also a predictor of suicide risk and mental health distress. In a recent study, Rimes et al. found that stigma and discrimination experiences, including the experience of stigmatizing behavior in schools, were associated with suicide attempts, ideation and future risk among sexual minority youth (Rimes et al., 2018). Feeling safe at school might also protect against suicidality. Taliaferro \& Muehlenkamp (2017) found that feeling safe at school reduced risk of suicidality and repetitive NSSI.

\subsubsection{Gender dysphoria and seeking affirmative care}

Gender dysphoria occurs when one feels discomfort due to incongruence between gender identity and sex assigned at birth and/or sex characteristics (APA, 2015). While not all TGD youth experience gender dysphoria, many youth feel profound distress particularly during adolescence when secondary sex characteristics are developed (Drescher \& Byne, 2012; Littman, 2018; Steensma et al., 2011). Gender dysphoria is one factor that has been associated with suicide risk among TGD youth samples (Aitkin et al., 2016; Petersen, et al., 2017). Fortunately, significant medical advances in gender affirming care (e.g., puberty suppression, cross-sex hormones, gender affirming surgeries) and affirmative therapy practices (e.g., Singh \& Dickey, 2017) have allowed youth to feel more supported and congruent in their sexual and gender experiences, protecting against the risk of suicide (Steensma et al., 2011).

However, challenges and barriers often prevent access to this care. Access is often limited due to policy issues and gatekeeping by family members or clinical professionals (Klein \& Golub, 2016; Simons et al., 2013). In terms of policy, caregiver, and provider barriers, youth must seek permission to receive the services they need to feel their bodies are congruent with their gender identities and, therefore, reduce feelings of gender dysphoria. Unfortunately, many providers are ill-equipped to support their patients in obtaining this care and youth must rely on rejecting or ambivalent caregivers (e.g., caregivers, guardians, extended family, adult family members of choice) to make decisions about their medical care and/or physical, social, or legal transitioning (Drescher \& Byne, 2012; Simons et al., 2013). These risk factors can lead to many youth feeling hopeless, depressed, and, in some cases, suicidal.

\subsubsection{Familial factors}

The impact of caregiver behavior on youth suicidality is welldocumented. A substantial amount of research has linked caregiver criticism, control, emotional unresponsiveness, absence of support, and rejection to adolescent suicidality in the general population (Connor \& Rueter, 2006; Kerr et al., 2006). Indeed, Brent et al. (1988) found that $20 \%$ of adolescent suicides and $50 \%$ of non-fatal suicide attempts were preceded by conflict with caregivers.

LGBTQIA + youth may be particularly at-risk for conflict with caregivers, criticism and rejection. Some caregivers, particularly those who ascribe to gender binarism, may perceive their child's attractions or expressions as unnatural, unacceptable, immoral and/or dangerous. While many caregivers may eventually become more accepting and affirming of their child's identities (Herdt \& Koff, 2000; Holtzen \& Agresti, 1990; Robinson et al., 1989), up to $40 \%$ are initially rejecting or intolerant (D'Augelli, 2003; D'Augelli et al., 1998). As with heterosexual and cisgender youth, among sexual and gender minorities, criticism, control, unresponsiveness and rejection have been consistently linked to suicide risk (Klein \& Golub, 2016; Mustanski \& Liu, 2013; Russell \& Toomey, 2013; Yadegarfard et al., 2014). Findings from a recent study revealed that sexual minority youth, who experienced maltreatment from caregivers, were 9.5 times more likely to attempt suicide compared to sexual minority youth with supportive caregivers (Puckett et al., 
2017). In contrast, caregiver support is incredibly protective against suicide risk (Mustanski \& Liu, 2013; Ryan, 2009; Smithee et al., 2019). Indeed, families are among the most immediate youth social networks and have the potential to be a life-saving resource. Lytle et al. (2017) found social support from caregivers predicted reduced suicide behaviors and increased help seeking far more than social support from friends. Research has also shown that sexual minority adolescents who report high levels of caregiver support and good communication, reported fewer mental health symptoms (Feinstein et al., 2014). Furthermore, such caregiver support has been shown to buffer against the negative effects of identity-related victimization (D'Augelli, 2003; Evans et al., 2005). Recently, Taliaferro and Muehlenkamp (2017) demonstrated that parent connectedness protected against self-harming behaviors for sexual minority youth. It was also found that feeling connected to nonparental adults (i.e., adult relatives, adults in the community) reduced the risk of repetitive non-suicidal self-injury and suicidality. In sum, family factors are unequivocally associated with suicide risk.

\section{Method}

Previous reviews on the suicide risk and mental health of LGBTQIA+ populations have yet to address specific clinical interventions for suicide risk in this population (Aranmolate et al., 2017; Fox et al., 2020; Plöderl et al., 2014). Recent reviews have already examined general psychotherapeutic interventions (Bochicchio et al., 2020; Hobaica et al., 2018) as well as depression interventions for this population (Sheinfil et al., 2019). A review of family-based interventions for youth suicidal ideation and behavior was conducted by Frey and Hunt (2018), but was not focused on LGBTQIA + youth. In 2016, Marshall conducted a review of prevention interventions for sexual and gender minority youth; however, this review did not include clinical treatments to address active suicidality. This current structured review aims to add to this body of literature by describing, in depth, the interventions that have been developed or adapted to treat suicide among LGTBQ+ youth. Using this information, we will then illustrate the strengths and limitations in this current body of literature.

This structured review included an extensive search of six electronic databases recommended by our consulting librarian, including PubMed from NLM as well as the following databases from EBSCOhost: PsychINFO, Child Development \& Adolescent Studies, Psychology \& Behavioral Sciences Collection, Family \& Society Studies Worldwide. We utilized a comprehensive search strategy that combined search terms which included youth, adolescents, young people, teen, young adults; treatment, therapy, intervention, psychotherapy, or psychological intervention; suicide, suicidality, suicidal ideation, suicide attempts, self-injurious, or self-harm; LGBTQ, LGBTQIA, lesbian, gay, homosexual, bisexual, transgender, queer, sexual minority, gender minority, or trans. After selecting articles written in English, within the past 20 years, and removing duplicates, approximately 200 articles met the criteria in our search terms. A secondary review selected only peer-reviewed intervention studies that 1) focused on psychotherapy treatment studies targeting suicide (e.g., ideation, attempts, and/or behavior) as a primary outcome, and 2) treatments modified or applied intentionally for LGBTQIA + youth.

As demonstrated in previous systematic reviews (e.g., Hobaica et al., 2018; Sheinfil et al., 2019) treatment research focused on this population is limited. This is particularly true for suicide-specific treatments. Only one suicide treatment had been adapted and tested for LGBTQ+ youth. While several other treatments target concerns related to suicide (e.g., self-esteem, depression, health behaviors), none have been designed to target suicidality and few have measured suicide outcomes in clinical research.

To bolster our review, we also conducted a search on NIH RePORTER using the terms, (treatment OR therapy OR intervention OR psychotherapy OR psychological intervention) AND (suicide OR suicidal ideation OR suicide attempts OR self-injurious OR suicidality) AND (LGBTQ OR sexual minority OR gender minority OR gay OR transgender) AND (youth OR young adult OR adolescents). This search yielded 35 results; however, few were suicide intervention studies.

\section{Treatment research}

Given the prevalence and severity of suicide among LGBTQIA+ youth, surprisingly few intervention models have been developed and tested for this population (Marshall, 2016). Due to the paucity of suicide-specific treatments for LGBTQIA+ youth, we turn first to approaches for youth depression and other outcomes related to suicidality (e.g., self-esteem, social support). These LGBTQIA + sensitive treatments could be possible candidates for suicide intervention. A variety of approaches have been developed or adapted to address specific health outcomes (e.g., substance use, sexual health) among sexual and gender minority youth. Fewer have targeted depression, but preliminary results from several approaches have demonstrated promising results. Before describing the literature on these treatments, we provide a possible explanation for the paucity of clinical research based on our review of theory and the factors associated with suicide for this population.

Developing effective treatment and research retention is complicated by mistrust of researchers and family rejection that lowers the odds of seeking treatment for LGBTQIA+ youth (Olson-Kennedy et al., 2017). Several reasons may account for this. First, LGBTQIA+ communities have historically been left out of clinical trials due to skepticism of researchers outside of LGBTQIA+ communities (Craig et al., 2019; OlsonKennedy et al., 2017; Oransky et al., 2019; Russon et al., 2019). These youth and the providers that treat them have ambivalence about the research community which is further compacted by the proximal and distal stressors outlined in MST. The stress has undoubtedly been fueled by experiences with academic communities. LGBTQIA+ individuals often report feeling exploited by academic who often come to "study them" and then leave. Clearly the researchers could do more to build safe and collaborative relationships with this community; however, the problem is also embedded in the established structures for conducting research in our institutions. Second, LGBTQIA + individuals, particularly TGD youth, rarely seek general community behavioral health services (Craig et al., 2019; Oransky et al., 2019; Russon et al., 2019). They report feeling misunderstood, and unwelcome. In addition, for many adolescents to have access to these services, caregivers must be involved to some extent. For those youth living in rejecting or critical families, this may be particularly difficult. Lytle et al. (2017) found that only $27.4 \%$ of cisgender gay, bisexual, or queer men and $24 \%$ of cisgender lesbian, bisexual, or queer women sought family support for their mental health. For transgender youth, only $8.3 \%$ report turning to their families for support to seek services. These kinds of problems contribute to low treatment retention (Olson-Kennedy, 2016), minimal and helpseeking for common problems like depression, suicidality or substance abuse remains difficult (Shipherd et al., 2010), and, perhaps the onset or exacerbation of thwarted belongingness and perceived burdensomeness. Fortunately, there are some promising programs of research that have attempted to address minority stress, and strengthen connectedness in suicide treatments.

\subsection{Treatments for depression and suicide}

Several cognitive-behavioral therapy (CBT) approaches have been developed and tested. Affirmative Supportive Safe and Empowering Talk (ASSET; Craig, 2013) is a group counseling intervention that has been designed for school settings to address sexual minority specific health concerns (Craig et al., 2014). Strengths First is a strength-based case management prevention intervention that aims to increase selfefficacy and self-esteem (Craig et al., 2012). Craig and Furman (2018) examined the program acceptability of ASSET (group therapy) and Strengths First (SF) care coordination through an investigation of client 
files who attended one of the programs between 2008 and 2010. One major benefit of this program is that the researchers found that acceptability was high for participants and did not differ across gender identity, sexual orientation, or race (Craig \& Furman, 2018). Both SF and ASSET group therapy were strengths-based and provided confidence, mentors, community, and social support, which helped to make the programs acceptable and affirming (Craig \& Furman, 2018). However, SF significantly increased problem-solving skills compared to ASSET group therapy (Craig \& Furman, 2018). Both interventions demonstrated significant increases in self-esteem. Within this study, only two of over 200 participants identified as TGD, making the results of acceptability potentially less generalizable to gender minority youth. Smith et al. (2017) published findings from another CBT group approach. Project Pride has shown promising results for gay and bisexual young adults. This eight session group targets coping and minority-stress. It utilizes cognitive reframing, role play, and psychoeducation to improve mental health outcomes. While the group aimed to improve mental health, depression and suicidality were not required for participation.

Another CBT-based approach, Trauma-Focused CBT (TF-CBT; Cohen, Deblinger, \& Mannarino, 2018), has been integrated with the Family Acceptance Project (FAP; Ryan, 2014) in order to better work with LGBTQIA+ youth who have experienced trauma and their caregivers (Cohen, Mannarino, et al., 2018). When studied internationally in thirteen experimental treatment trials, TF-CBT led to decreases in depressive and anxiety symptoms, as well as other PTSD symptoms, in children and adolescents (Cohen, Deblinger, \& Mannarino, 2018). The FAP initiative was originally developed for LGBTQIA+ youth and their families to help families support the youths' health and wellness (Cohen, Mannarino, et al., 2018). FAP specifically focuses on how families demonstrate acceptance and rejection of their LGBTQIA + children, and found that rejecting behaviors were associated with risk (e.g. previous suicide attempts, depression, illegal drug use, and contracting sexually transmitted infections), and accepting behaviors were associated with well-being (Ryan, 2014). Based on initial data, the integration of TF-CBT and FAP has potential to improve LGBTQIA+ youth PTSD symptoms (Cohen, Mannarino, et al., 2018).

Effective Skills to Empower Effective Men (ESTEEM; Pachankis et al., 2015 ) is a pragmatic, skills-based approach for young gay and bisexual men. The treatment targets stressors related to stigma and marginalization that contribute to depression and unhealthy coping behaviors. In a 2015 randomized clinical trial, ESTEEM reduced depression, alcohol use and sexual minority-specific stressors. Online CBT interventions have also shown some promise. Rainbow SPARX (i.e., smart, positive, active, realistic, $\mathrm{x}$-factor thoughts) is a computer-based CBT program targeting depression, anxiety, and hopelessness among minority youth (Lucassen et al., 2015). This online CBT approach was specifically adapted to sexual minority youth after a series of focus groups. In a small study, Rainbow SPARX was tested with 21 LGBQ youth who completed seven models focused on CBT strategies. Results revealed significant decreases in all outcomes. Reductions in depression held at 3-month follow-up. These findings are important, given that online programming is often very accessible for LGBTQIA + youth.

The Community Reinforcement Approach (CRA; Grafsky et al., 2011) targets substance abuse and mental health for homeless youth. In a 2011 trial of the CRA program, both heterosexual participants and lesbian, gay, bisexual, and queer participants received 12 therapy sessions. The program also included psychoeducation, social counseling, and relapse prevention. Optional involvement of an adult mentor was offered. No programmatic adaptations were made specifically for LGBTQ IA+ youth (Hobaica et al., 2018). Participants in TAU received resource coordination and case management sessions. Findings revealed that in both conditions, heterosexual youth and lesbian, gay, bisexual, and queer youth showed reductions in drug use, depression and internalizing symptoms.

Last year, some new intervention research was published. A study published by Pachankis et al. (2020) described a brief online intervention for sexual minority mental health. This study tested the efficacy of expressive writing and self-affirmation as two self-guided online interventions. Compared to a control group, participants who engaged in written self-affirmations showed improvement in drug abuse and suicidal ideation (Pachankis et al., 2020). Pepping et al. (2017) published a study describing a randomized controlled trial testing the efficacy of a compassion-focused therapy intervention with sexual minority young adults with depressive symptoms. While this research measures suicide, this article describes the study design rather than outcome data. Results from this study have not yet been published.

While these treatments have their strengths, few have included large groups of TGD youth. Affirmative group-based cognitive-behavioral therapy (AFFIRM; Austin et al., 2018) is one of the only promising treatments for sexual and gender minority youth. This model targets LGBTQIA+ stressors by helping clients to recognize, understand, and change the relationship between homophobic and transphobic experiences and feelings of anxiety, stress, depression, and hopelessness (Austin \& Craig, 2015a, 2015b; Craig \& Austin, 2016). Craig and Austin (2016) found the model to be acceptable and feasible for lesbian, gay, bisexual, and queer youth and a smaller subsample of TGD youth. Austin et al. (2018) then further developed the AFFIRM model to: (a) center on the unique experiences of navigating gender and sexuality in youth and adolescence, (b) recognize sexual and gender specific stressors (e.g., transphobia and homophobia), and (c) to affirm sexual and gender minority identities, and (d) deliver CBT within an affirmative context that attends to issues of identity. The model was then tested with 30 sexual and gender minority youth, eight of whom were TGD. Delivery considerations, specific to the needs of TGD youth, were included in the AFFIRM manual (e.g., availability of gender-neutral bathrooms, use of pronouns during staff introductions). AFFIRM demonstrated preliminary effectiveness in reducing depression. Recently, Craig et al. (2019) designed another study to test the efficacy of AFFIRM on improving the mental health of gender and sexual minority youth. While this implementation study was designed to reduce sexual risk behaviors and psychosocial distress, no suicide outcomes measured.

\subsection{Attachment-based family therapy}

One suicide-specific youth treatment approach has been modified for sexual and gender minority youth and also targets minority stressors in the family context, as well as the quality of interpersonal experiences. Attachment-Based Family Therapy (ABFT; Diamond et al., 2014) is an emotion-focused, empirically supported treatment that aims to repair interpersonal ruptures in caregiver-child relationships. ABFT is designed to improve the family's capacity for affect regulation, interpersonal problem-solving, and the negotiation of attachment and autonomy. These improved capacities strengthen family cohesion, which can buffer against depression, suicidal thoughts, and risky behaviors (Restifo \& Bögels, 2009). Once relationship ruptures are repaired, the later stages of treatment emphasize autonomy-building and identity development. The model was specifically designed to address adolescent suicide, depression, and trauma, but has been adapted to be used with other presenting problems (Diamond et al., 2016).

Using five treatment tasks, ABFT aims to repair ruptures in the attachment relationship and establish or resuscitate a secure, familybased environment. This work can reduce family stress and increase utilization of the family to buffer against stressors outside the home (e.g. bullying, discrimination). The model has also evolved over 15 years of research to evaluate its efficacy, effectiveness, processes, and mechanism of change (see Diamond et al., 2016 for a review). ABFT has been adapted for lesbian, gay, bisexual, and queer adolescents (Diamond et al., 2012), demonstrated clinical utility for sexual and gender minority youth presenting in ABFT clinical trials (Diamond et al., 2019), and is currently being adapted for TGD youth (Russon et al., 2019).

Initial efforts have focused on modification and evaluation of ABFT 
for sexual and gender minority youth populations. Diamond et al. (2012) sought to adapt the model to address the core relational themes associated with ruptures between lesbian, gay, bisexual, and queer youth and their caregivers. Initially, a qualitative study examined how depressed and suicidal lesbian, gay, bisexual, and queer adolescents understood the causes of their distress (Diamond et al., 2012). These adolescents attributed their symptoms to a) quality of their relationship with their caregiver(s), b) family rejection of sexual identity, c) negative familial events unrelated to sexual identity and d) extra-familial victimization. Youth also reported that they wished to have a closer relationship with their caregivers. In a following pilot study, Diamond et al. (2012) modified the model and tested treatment feasibility, acceptability and preliminary efficacy. This study was conducted at the same site where the model first emerged. Results showed high levels of treatment retention as well as significant decreases in a) suicidal ideation, b) depression, and c) attachment-related anxiety and avoidance.

Recently, the feasibility and acceptability of ABFT was tested with a small sample of TGD youth as part of an implementation pilot study (Russon et al., 2019). In this study, the delivery of ABFT was adapted for LGBTQIA+ service organizations and, then, was and implemented across three sites. ABFT was tested with 10 LGBTQIA+ youth, seven of whom identified as both sexual and gender minorities. Youth enrolled in the trial endorsed severe levels of suicidal ideation and moderate to severe depression. The majority of cases reported at least one previous suicide attempt. All enrolled youth and caregivers completed treatment and attended an average of 15 sessions each; therefore meeting or exceeding other clinical studies for suicidal youth (Diamond et al., 2012, 2019; Donaldson et al., 2005; Spirito et al., 2002). There were no treatment dropouts. Results further revealed that patients and caregivers were satisfied with treatment and perceived ABFT to be a credible, helpful approach. With regard to treatment effectiveness, suicidal ideation decreased over the course of treatment. Depression did not decrease, but showed some decreased tendency over treatment.

The pilot by Russon et al. (2019) revealed family-based challenges unique to TGD youth that perhaps explained why there were not reductions in depression. First, following relationship repair, more time in treatment may have been needed to address complex needs of TGD families, many of whom were a) negotiating physical, social and or legal transition and b) managing anxiety related to engaging with potentially stigmatizing social systems (e.g. schools, hospitals, healthcare systems etc.). Such challenges are common to many TGD youth and their families (Berry, 2018; Hines et al., 2019). Second, although ABFT proved acceptable to caregivers, they were also experiencing significant stress and burden at the time of treatment. Russon et al. (2019) concluded that participating caregivers needed additional support to manage their own challenges, fears or barriers associated with their youth's care. Working with caregivers of the TGD youth generated specific treatment adaptations above and beyond those identified in G.M. Diamond's (2012) adaptation study (Russon \& Holubec, 2019).

\subsection{Treatments in development}

According to our search in RePORTER, few behavioral or psychotherapy intervention studies focused on sexual minority and gender youth suicide were found, though several focused on self-harm (PI: Behar-Zusman). The suicide treatment studies for this population are as follows. One PI (Santisteban) is testing the efficacy of a computerassisted and culturally-informed intervention on non-suicidal selfinjury and non-fatal suicide attempts of Latinx LGBTQ+ youth. Another PI (Blashill) is adapting and testing an intervention that combines patient navigation and Safety Planning to address IPTS mechanisms that contribute to suicidality among sexual and gender minority youth. Finally, in another study, efforts have been made to combine data across intervention trials examining suicide risk. The PI (Brown) is investigating whether sexual and gender minority youth receive differential benefits from the treatments under study. Findings from this ongoing research have yet to be published.

\section{Limitations and future directions}

Treatment research addressing suicide among LGBTQIA+ youth remains in its infancy. The few existing pilot studies focus primarily on feasibility and acceptability with sample sizes too small to demonstrate efficacy. Three additional limitations should be noted. First, the current body of literature has not always differentiated between the needs of specific identities within the LGBTQIA+ "umbrella." For example, few studies had samples where TGD youth were well-represented. The participation of intersex youth has not been reported in treatment literature, and most approaches are focused on treating LGBTQIA+ youth broadly.

Second, of the treatments developed for this population, few include families in the intervention. Given that caregivers clearly impact mental health outcomes among LGBTQIA+ youth, it is surprising that they are not a focal point of treatment. This is especially true because many LGBTQIA + adolescents and young adults live, or interact frequently, with their caregivers and/or families of choice. As described earlier in this review, sexual and gender minority youth attribute their suicidal thoughts and behaviors to quality of their relationships with caregivers, familial rejection, negative familial interactions, and victimization (Diamond et al., 2012). Even when family factors are not the cause of distress, many LGBTQIA + youth do not turn to their caregivers for help managing heterosexism, transphobia or victimization, fearing caregivers will not protect and/or understand them (Hammelman, 1993; Hunter \& Schaecher, 1987; Savin-Williams, 1989, 1994). This prohibits caregivers from being a resource to their LGBTQIA+ children as they navigate these complex social issues. From a suicide management perspective, this disconnection also poses a major safety issue. Caregivers, including families of choice, can initiate effective suicide monitoring and service utilization for their children (King et al., 2018; LeCloux et al., 2016). Unfortunately, familial discord may hinder possibilities for keeping youth safe in their homes and communities. In sum, these limitations warrant future attention, given the high rates of suicide attempts among LGBTQIA + youth and the importance of more culturally-sensitive, tailored suicide treatment efforts in the future.

Finally, while suicide prevention literature targets the impact of macrosystems (Marshall, 2016), the body of research on suicide treatment generally remains focused on LGBTQIA+ individuals rather than the socioecological problem. MST demonstrates how disparities in suicide risk among LGBTQIA+ youth are socially produced through stressors within youths' environments and the internalization of stigma. Tilsen (2013) suggests that diagnosing transphobic and homophobic discourses, such as the example of "Gender Inflexibility Disorder," could serve as a powerful therapeutic strategy to shift the responsibility for ensuring the well-being of LGBTQIA+ individuals to the systems currently responsible for perpetrating these harmful discourses (pp. 100-101). Future research on therapeutic interventions that target the impact of macrosystems on LGBTQIA+ youth suicide, rather than focusing primarily on the individual, may better address the transphobic and homophobic social discourses that perpetuate disparities in suicide risk.

We have several additional recommendations for future research. As described in this review, there are many barriers to LGBTQIA+ youth receiving care in community mental health settings and youth may be more likely to turn to LGBTQIA+ organizations (Craig et al., 2019; Oransky et al., 2019; Russon et al., 2019). To date, little is known about the suicide readiness of settings and organizations that see the majority of these populations. It is unclear how these approaches could fit within the existing structures of these settings. Though many medical practices are underprepared for suicide identification, management and/or treatment, LGBTQIA+ organizations may have unique cultural and clinical demands working with largely underserved populations. In light of these current limitations, our recommendations for future research 
are twofold. First, researchers should continue to adapt and test promising approaches for specific identities within the LGBTQIA+ "umbrella." Second, researchers should seek to better understand the systems of care in which LGBTQIA + youth receive services. These efforts will support the development of approaches and delivery methods that are well-suited for uptake in these settings and, therefore, best address suicide among LGBTQIA+ youth.

\section{Conclusion}

The body of literature on empirically-supported treatments addressing suicide among LGBTQIA + youth is growing. Although several approaches for suicide and other mental health concerns have been adapted and tested for these populations, sample sizes are small and studies have overwhelmingly been focused on sexual minority youth. Few approaches have targeted or engaged families and/or the immediate social networks that could support youth struggling with suicide. Further, as this body of clinical research is small, little attention has been directed toward the implementation of such approaches into the service settings where LGBTQIA+ youth are most likely to receive care. It is recommended that future research efforts aim to modify promising suicide-specific treatments for LGBTQIA+ youth and seek to evaluate the fit of these treatments in organizations serving this population.

\section{Funding sources}

This research did not receive any specific grant from funding agencies in the public, commercial, or not-for-profit sectors.

\section{CRediT authorship contribution statement}

Jody Russon, PhD: Conceptualization, Visualization, Project Administration, Investigation, Writing - Original Draft Preparation. Regina Washington, DrPH: Visualization, Writing - Review \& Editing. Ana Machado, MPH: Visualization, Writing- Review \& Editing. Lauren Smithee, MS: Writing - Original Draft Preparation, Writing- Review \& Editing, Investigation. Jamie Dellinger, MFT: Writing - Original Draft Preparation, Investigation.

\section{Declaration of competing interest}

None.

\section{Acknowledgements}

We would like to thank Dr. Guy Diamond for his contribution to this manuscript.

\section{References}

Abreu, R. L., \& Kenny, M. C. (2017). Cyberbullying and LGBTQ youth: A systematic literature review and recommendations for prevention and intervention. Journal of Child \& Adolescent Trauma, 11, 81-97. https://doi.org/10.1007/s40653-017-0175-7

Aitken, M., VanderLaan, D. P., Wasserman, L., Stojanovski, S., \& Zucker, K. J. (2016). Self-harm and suicidality in children referred for gender dysphoria. Journal of the American Academy of Child \& Adolescent Psychiatry, 55(6), 513-520. https://doi.org/ 10.1016/j.jaac.2016.04.001

Almeida, J., Johnson, R. M., Corliss, H. L., Molnar, B. E., \& Azrael, D. (2009). Emotiona distress among LGBT youth: The influence of perceived discrimination based on sexual orientation. Journal of Youth and Adolescence, 38, 1001-1014. https://doi. org/10.1007/s10964-009-9397-9

American Psychological Association. (2012). Guidelines for psychological practice with lesbian, gay, and bisexual clients. American Psychologist, 67(1), 10-42. https://doi. org/10.1037/a0024659

American Psychological Association. (2015). Guidelines for psychological practice with transgender and gender nonconforming people. American Psychological Association, 70, 832-864. https://doi.org/10.1037/a0039906

Aranmolate, R., Bogan, D. R., Hoard, T., \& Mawson, A. R. (2017). Suicide risk factors among LGBTQ youth. JSM Schizophrenia, 2(2), 1011.
Austin, A., \& Craig, S. L. (2015a). Empirically supported interventions for sexual and gender minority youth. Journal of Evidence-Informed Social Work, 12, 567-578. https://doi.org/10.1080/15433714.2014.884958

Austin, A., \& Craig, S. L. (2015b). Transgender affirmative cognitive behavioral therapy: Clinical considerations and applications. Professional Psychology: Research and Practice, 46, 21-29. https://doi.org/10.1037/a0038642

Austin, A., Craig, S. L., \& D'Souza, S. A. (2018). An AFFIRMative cognitive behavioral intervention for transgender youth: Preliminary effectiveness. Professional Psychology: Research and Practice, 49(1), 1-8. https://doi.org/10.1037/pro0000154

Baams, L., Grossman, A. H., \& Russell, S. T. (2015). Minority stress and mechanisms of risk for depression and suicidal ideation among lesbian, gay, and bisexual youth. Developmental Psychology, 51, 688-696. https://doi.org/10.1037/a0038994.

Berry, K. (2018). LGBT bullying in school: A troubling relational story. Communication Education, 67(4), 502-513. https://doi.org/10.1080/03634523.2018.1506137

Blumer, M. L., Gavriel Ansara, Y., \& Watson, C. M. (2013). Cisgenderism in family therapy: How everyday clinical practices can delegitimize people's gender selfdesignations. Journal of Family Psychotherapy, 24(4), 267-285.

Bochicchio, L., Reeder, K., Ivanoff, A., Pope, H., \& Stefancic, A. (2020). Psychotherapeutic interventions for LGBTQ+ youth: A systematic review. Journal of LGBT Youth, 1-28. doi.org/10.1080/19361653.2020.1766393.

Boeninger, D. K., Masyn, K. E., Feldman, B. J., \& Conger, R. D. (2010). Sex differences in developmental trends of suicide ideation, plans, and attempts among European American adolescents. Suicide and Life-threatening Behavior, 40(5), 451-464.

Brent, D. A., Perper, J. A., Goldstein, C. E., Kolko, D. J., Allan, M. J., Allman, C. J., \& Zelenak, J. P. (1988). Risk factors for adolescent suicide: A comparison of adolescent suicide victims with suicidal inpatients. Archives of General Psychiatry, 45(6), 581-588. https://doi.org/10.1001/archpsyc.1988.01800300079011

Butler, J. (1990). Gender trouble. Routledge.

CDC. (2016). Sexual identity, sex of sexual contacts, and health-related behaviors among students in grades 9-12 - United States and selected sites, 2015. Morbidity and Mortality Weekly Report Surveillance Summaries, 65(9), 1-202. https://doi.org/10. 15585/mmwr.ss6509a1.

Cheek, S. M., Nestor, B. A., \& Liu, R. T. (2016). Substance use and suicidality: Specificity of substance use by injection to suicide attempts in a nationally representative sample of adults with major depression. Depression and Anxiety, 33, 541-548. https://doi.org/10.1002/da.22407

Chu, C., Buchman-Schmitt, J. M., Stanley, I. H., Hom, M. A., Tucker, R. P., Hagan, C. R., Joiner, T. E. (2017). The interpersonal theory of suicide: A systematic review and meta-analysis of a decade of cross-national research. Psychological Bulletin, 143, 1313-1345. https://doi.org/10.1037/bul0000123

Cohen, J. A., Deblinger, E., \& Mannarino, A. P. (2018). Trauma-focused cognitive behavioral therapy for children and families. Psychotherapy Research, 28(1), 47-57. https://doi.org/10.1080/10503307.2016.1208375

Cohen, J. A., Mannarino, A. P., Wilson, K., \& Zinny, A. (2018). Trauma-focused cognitive behavioral therapy LGBTQ implementation manual. Pittsburgh, PA: Allegheny Health Network.

Connor, J. J., \& Rueter, M. A. (2006). Parent-child relationships as systems of support or risk for adolescent suicidality. Journal of Family Psychology, 20, 143-155. https:// doi.org/10.1037/0893-3200.20.1.143

Craig, S. L. (2013). Affirmative supportive safe and empowering talk (ASSET): Leveraging the strengths and resiliencies of sexual minority youth in school-based groups. Journal of LGBT Issues in Counseling, 7(4), 372-386.

Craig, S. L., Austin, A., \& McInroy, L. B. (2014). School-based groups to support multiethnic sexual minority youth resiliency: Preliminary effectiveness. Child \& Adolescent Social Work Journal, 31, 87-106. https://doi.org/10.1007/s10560-0130311-7

Craig, S. L., \& Furman, E. (2018). Do marginalized youth experience strengths in strengths-based interventions? Unpacking program acceptability through two interventions for sexual and gender minority youth. Journal of Social Service Research, 44, 168-179. https://doi.org/10.1080/01488376.2018.1436631

Craig, S. L., McInroy, L., Austin, A., Smith, M., \& Engle, B. (2012). Promoting self-efficacy and self-esteem for multiethnic sexual minority youth: An evidence-informed intervention. Journal of Social Service Research, 38, 688-698. https://doi.org/ 10.1080/01488376.2012.718194

Craig, S. L., \& Austin, A. (2016). The AFFIRM open pilot feasibility study: A brief affirmative cognitive behavioral coping skills group intervention for sexual and gender minority youth. Children and Youth Services Review, 64, 136-144. https://doi. org/10.1016/j.childyouth.2016.02.022

Craig, S. L., McInroy, L. B., Eaton, A. D., Iacono, G., Leung, V. W. Y., Austin, A., \& Dobinson, C. (2019). An affirmative coping skills intervention to improve the mental and sexual health of sexual and gender minority youth (Project Youth AFFIRM): Protocol for an implementation study. JMIR Research Protocols, 8, 134-162. https:// doi.org/10.2196/13462

Cramer, R. J., Stroud, C. H., Fraser, T., \& Graham, J. (2014). A trait-interpersonal analysis of suicide proneness among lesbian, gay, and bisexual community members. Suicide and Life-threatening Behavior, 44(6), 601-615.

D'Augelli, A. R. (2003). A Crash Course on Sexual Orientation and Sexual Identity. Psychology of Women Quarterly,27(1), 81-82.

D'Augelli, A. R., Hershberger, S. L., \& Pilkington, N. W. (1998). Lesbian, gay, and bisexual youth and their families: Disclosure of sexual orientation and its consequences. The American Journal of Orthopsychiatry,68(3), 361-71.

DeCamp, W., \& Bakken, N. W. (2016). Self-injury, suicide ideation, and sexual orientation: Differences in causes and correlates among high school students. Journal of Injury and Violence Research., 8(1), 15-24. https://doi.org/10.5249/jivr.v8i1.545 
Diamond, G., Russon, J., \& Levy, S. (2016). Attachment-based family therapy: A review of the empirical support. Family Process, 55, 595-610. https://doi.org/10.1111/ famp. 12241

Diamond, G. M., Diamond, G. S., Levy, S., Closs, C., Ladipo, T., \& Siqueland, L. (2012) Attachment-based family therapy for suicidal lesbian, gay, and bisexual adolescents: A treatment development study and open trial with preliminary findings. Psychotherapy, 49, 62-71. https://doi.org/10.1037/a0026247

Diamond, G. S., Diamond, G. M., \& Levy, S. A. (2014). Attachment-based family therapy for depressed adolescents. American Psychological Association.

Diamond, G. S., Kobak, R. R., Ewing, E. S. K., Levy, S. A., Herres, J. L., Russon, J. M., \& Gallop, R. J. (2019). A randomized controlled trial: Attachment-based family and nondirective supportive treatments for youth who are suicidal. Journal of the American Academy of Child \& Adolescent Psychiatry, 58(7), 721-731.

Donaldson, D., Spirito, A., \& Esposito-Smythers, C. (2005). Treatment for adolescents following a suicide attempt: Results of a pilot trial. Journal of the American Academy of Child \& Adolescent Psychiatry, 44(2), 113-120. https://doi.org/10.1097/ 00004583-200502000-00003

Drescher, J., \& Byne, W. (2012). Gender dysphoric/gender variant (GD/GV) children and adolescents: Summarizing what we know and what we have yet to learn. Journal of Homosexulaity, 59(3). https://doi.org/10.1080/00918369.2012.653317

Evans, E., Hawton, K., Rodham, K., Psychol, C., \& Deeks, J. (2005). The prevalence of suicidal phenomena in adolescents: A systematic review of population-based studies. Suicide and Life-threatening Behavior, 35, 239-250. https://doi.org/10.1521/ suli.2005.35.3.239

Family Acceptance Project. (2020, August). Research: In-depth family interviews, case studies and surveys. Family Acceptance Project. https://familyproject.sfsu.edu/resea rch.

Farmer, L. B., \& Byrd, R. (2015). Genderism in the LGBTQQIA community: An interpretative phenomenological analysis. Journal of LGBT Issues in Counseling, 9(4), 288-310.

Feinstein, B. A., Wadsworth, L. P., Davila, J., \& Goldfried, M. R. (2014). Do parental acceptance and family support moderate associations between dimensions of minority stress and depressive symptoms among lesbians and gay men? Professional Psychology: Research and Practice, 45, 239-246. https://doi.org/10.1037/a0035393

Fox, K. R., Choukas-Bradley, S., Salk, R. H., Marshal, M. P., \& Thoma, B. C. (2020). Mental health among sexual and gender minority adolescents: Examining interactions with race and ethnicity. Journal of Consulting and Clinical Psychology, 88 (5), 402. https://doi.org/10.1037/ccp0000486402.

Frey, L. M., \& Hunt, Q. A. (2018). Treatment for suicidal thoughts and behavior: A review of family-based interventions. Journal of marital and family therapy, 44(1), 107-124. doi.org/10.1111/jmft.12234.

Frost, D. M., Lehavot, K., \& Meyer, I. H. (2015). Minority stress and physical health among sexual minority individuals. Journal of Behavioral Medicine, 38(1), 1-8.

Goldblum, P., Testa, R. J., Pflum, S., Hendricks, M. L., Bradford, J., \& Bongar, B. (2012). The relationship between gender-based victimization and suicide attempts in transgender people. Professional Psychology: Research and Practice, 43(5), 468-475. https://doi.org/10.1037/a0029605

Grafsky, E. L., Letcher, A., Slesnick, N., \& Serovich, J. M. (2011). Comparison of treatment response among GLB and non-GLB street-living youth. Children and Youth Services Review, 33(5), 569-574. https://doi.org/10.1016/j.childyouth.2010.10.007

Grossman, A. H., \& D'Augelli, A. R. (2007). Transgender youth and life-threatening behaviors. Suicide and Life-Threatening Behavior, 37(5), 527-537. https://doi.org/ 10.1521/suli.2007.37.5.527

Grossman, A. H., Park, J. Y., \& Russell, S. T. (2016). Transgender youth and suicidal behaviors: Applying the interpersonal psychological theory of suicide. Journal of Gay \& Lesbian Mental Health, 20(4), 329-349. https://doi.org/10.1080/ 19359705.2016.1207581

Haas, A. P., Eliason, M., Mays, V. M., Mathy, R. M., Cochran, S. D., D’Augelli, A. R. Silverman, M. M., Fisher, P. W., Hughes, T., Rosario, M., Russell, S. T., Malley, E. Reed, J., Litts, D. A., Haller, E., Sell, R. L., Remafedi, G., Bradford, J., Beautrais, A. L. \& Brown, G. K. (2011). Suicide and suicide risk in lesbian, gay, bisexual, and transgender populations: Review and recommendations. Journal of Homosexuality, 58(1), 10-51. https://dx.doi.org/10.1080\%2F00918369.2011.534038.

Hall, W. J. (2018). Psychosocial risk and protective factors for depression among lesbian, gay, bisexual, and queer youth: A systematic review. Journal of homosexuality, 65 (3), 263-316. doi/https://doi.org/10.1080/00918369.2017.1317467.

Hammelman, T. L. (1993). Gay and lesbian youth: Contributing factors to serious attempts or considerations of suicide. Journal of Gay \& Lesbian Psychotherapy, 2(1), 77-89. https://doi.org/10.1300/J236v02n01 06

Harvey, R. G., \& Stone Fish, L. (2015). Queer youth in family therapy. Family Process, 54 396-417. https://doi.org/10.1111/famp.12170

Hatchel, T., Ingram, K. M., Mintz, S., Hartley, C., Valido, A., Espelage, D. L., \& Wyman, P. (2019). Predictors of suicidal ideation and attempts among LGBTQ adolescents: The roles of help-seeking beliefs, peer victimization, depressive symptoms, and drug use. Journal of Child and Family Studies, 28, 2443-2455. https://doi.org/10.1007/ s10826-019-01339-2

Hatchel, T., Valido, A., Pedro, K. T. D., Huang, Y., \& Espelage, D. L. (2018). Minority stress among transgender adolescents: The role of peer victimization, schoo belonging, and ethnicity. Journal of Child and Family Studies, 28, 2467-2476. https:// doi.org/10.1007/s10826-018-1168-3

Hendricks, M. L., \& Testa, R. J. (2012). A conceptual framework for clinical work with transgender and gender nonconforming clients: An adaptation of the minority stress model. Professional Psychology: Research and Practice, 43(5), 460-467. https://doi. org/10.1037/a0029597

Herdt, G., \& Koff, B. (2000). Between men-between women. In Something to tell you: The road families travel when a child is gay. Columbia University: Press.
Hill, R., \& Pettit, J. (2012). Suicidal ideation and sexual orientation in college students: The roleof perceived burdensomeness, thwarted belongingness, and perceived rejection due to sexual orientation. Suicide and Life-threatening Behavior, 42, $567-579$.

Hill, R. M., Rooney, E. E., Mooney, M. A., \& Kaplow, J. B. (2017). Links between social support, thwarted belongingness, and suicide ideation among lesbian, gay, and bisexual college students. Journal of Family Strengths, 17(2).

Hines, D. D., Laury, E. R., \& Habermann, B. (2019). They just don't get me: A qualitative analysis of transgender women's health care experiences and clinician interactions. The Journal of the Association of Nurses in AIDS Care, 30(5), e82. https://doi.org/ 10.1097/JNC.0000000000000023

Hobaica, S., Alman, A., Jackowich, S., \& Kwon, P. (2018). Empirically based psychological interventions with sexual minority youth: A systematic review. Psychology of Sexual Orientation and Gender Diversity, 5, 313-323. https://doi.org/ 10.1037/sgd0000275

Holtzen, D. W., \& Agresti, A. A. (1990). Parental Responses to Gay and Lesbian Children: Differences in Homophobia, Self-Esteem, and Sex-Role Stereotyping. Journal of Social and Clinical Psychology,9(3), 390-399.

Horwitz, A. G., Berona, J., Busby, D. R., Eisenberg, D., Zheng, K., Pistorello, J., ... \& King, C. A. (2020). Variation in suicide risk among subgroups of sexual and gender minority college students. Suicide and Life-Threatening Behavior. doi.org/10.1111/ sltb.12637.

Hunter, J., \& Schaecher, R. (1987). Stresses on lesbian and gay adolescents in schools. Social Work in Education, 9(3), 180-190.

James, S. E., Herman, J. L., Rankin, S., Keisling, M., Mottet, L., \& Anafi, M. (2016). The report of the 2015 U.S. transgender survey. Washington, DC: National Center for Transgender Equality.

Joiner, T. E. (2005). Why people die by suicide. Harvard University Press.

Jones, T. (2016). The needs of students with intersex variations. Sex Education, 16(6), 602-618.

Kerr, D., Preuss, L., \& King, C. (2006). Suicidal adolescents' social support from family and peers: Gender-specific associations with psychopathology. Journal of Abnormal Child Psychology, 34(1), 103-114. https://doi.org/10.1007/s10802-005-9005-8

King, C. A., Arango, A., \& Ewell Foster, C. (2018). Emerging trends in adolescent suicide prevention research. Current Opinion in Psychology, 22, 89-94. https://doi.org/ 10.1016/j.copsyc.2017.08.037

Kleiman, E. A., \& Liub, R. T. (2013). Social support as a protective factor in suicide: Findings from two nationally representative samples. Journal of Affective Disorders, 150, 540-545. https://doi.org/10.1016/j.jad.2013.01.033

Klein, A., \& Golub, S. A. (2016). Family rejection as a predictor of suicide attempts and substance misuse among transgender and gender nonconforming adults. LGBT Health, 3, 193-199. https://doi.org/10.1089/lgbt.2015.0111

LeCloux, M., Maramaldi, P., Thomas, K., \& Wharff, E. (2016). Family support and mental health service use among suicidal adolescents. Journal of Child and Family Studies, 25, 2597-2606. https://doi.org/10.1007/s10826-016-0417-6

Littman, L. (2018). Parent reports of adolescents and young adults perceived to show signs of a rapid onset of gender dysphoria. PLoS One, 13(8). https://doi.org/ 10.1371/journal.pone.0202330

Lucassen, M. F. G., Merry, S. N., Hatcher, S., \& Frampton, C. M. A. (2015). Rainbow SPARX: A novel approach to addressing depression in sexual minority youth. Cognitive and Behavioral Practices, 22(2), 203-216. https://doi.org/10.1016/j. cbpra.2013.12.008

Lytle, M. C., Silenzio, V. M. B., Homan, C. M., Schneider, P., \& Caine, E. D. (2017). Suicidal and help-seeking behaviors among youth in an online lesbian, gay, bisexual, transgender, queer, and questioning social network. Journal of Homosexuality, 65, 1916-1933. https://doi.org/10.1080/00918369.2017.1391552

Mandracchia, J. T., \& Smith, P. N. (2015). The interpersonal theory of suicide applied to male prisoners. Suicide and Life-threatening Behavior, 45(3), 293-301. https://doi. org/10.1111/sltb.12132

Marshall, A. (2016). Suicide prevention interventions for sexual \& gender minority youth: An unmet need. The Yale Journal of Biology and Medicine, 89(2), 205-213.

Matarazzo, B. B., Barnes, S. M., Pease, J. L., Russell, L. M., Hanson, J. E., Soberay, K. A., \& Gutierrez, P. M. (2014). Suicide risk among lesbian, gay, bisexual, and transgender military personnel and veterans: What does the literature tell us? The Official Journal of the American Association of Suicidology, 44(2), 200-217. https://doi.org/10.1111/ sltb. 12073

McDermott, E., \& Roen, K. (2012). Youth on the virtual edge: Researching marginalized sexualities and genders online. Qualitative Health Research, 22(4), 560-570.

McDermott, E., Hughes, E., \& Rawlings, V. (2018). Norms and normalisation: Understanding lesbian, gay, bisexual, transgender and queer youth, suicidality and help-seeking. Culture, Health \& Sexuality, 20(2), 156-172. https://doi.org/10.1080/ 13691058.2017 .1335435

Meyer, I. H. (2003). Prejudice, social stress, and mental health in lesbian, gay, and bisexual populations: Conceptual issues and research evidence. Psychological Bulletin, 129, 674-697. https://doi.org/10.1037/0033-2909.129.5.674

Meyer, I. H., Teylan, M., \& Schwartz, S. (2015). The role of help-seeking in preventing suicide attempts among lesbians, gay men, and bisexuals. Suicide and Life-threatening Behavior, 45, 25-36. https://doi.org/10.1111/sltb.12104

Miranda-Mendizabal, A., Castellví, P., Parés-Badell, O., Alayo, I., Almenara, J., Alonso, I., Lagares, C. (2019). Gender differences in suicidal behavior in adolescents and young adults: Systematic review and meta-analysis of longitudinal studies. International Journal of Public Health, 64(2), 265-283.

Mizock, L., \& Lundquist, C. (2016). Missteps in psychotherapy with transgender clients: Promoting gender sensitivity in counseling and psychological practice. Psychology of Sexual Orientation and Gender Diversity, 3, 148. 
Moss-Racusin, C. A., Phelan, J. E., \& Rudman, L. A. (2010). When men break the gender rules: Status incongruity and backlash against modest men. Psychology of Men \& Masculinity, 11(2), 140-151. https://doi.org/10.1037/a0018093

Muehlenkamp, J. J., Hilt, L. M., Ehlinger, P. P., \& McMillan, T. (2015). Nonsuicidal selfinjury in sexual minority college students: A test of theoretical integration. Child and Adolescent Psychiatry and Mental Health, 9(16). https://doi.org/10.1186/s13034. 015-0050-y

Mustanski, B., \& Liu, R. T. (2013). A longitudinal study of predictors of suicide attempts among lesbian, gay, bisexual, and transgender youth. Archives of Sexual Behavior, 42 (3), 437-448. https://doi.org/10.1007/s10508-012-0013-9.

Newfield, E., Hart, S., Dibble, S., \& Kohler, L., (2006). Female-to-male transgender quality of life. Quality of life Research, 15(9), 1447-1457. doi.org/10/1007/s11136006-002-3.

Nock, M., Green, J., Hwang, I., McLaughlin, K., Sampson, N., Zaslavsky, A., \& Kessler, R. (2013). Prevalence, correlates and treatment of lifetime suicidal behavior among adolescents: Results from the National Comorbidity Survey Replication - Adolescent supplement (NCS-A). JAMA Psychiatry, 70(3). https://doi.org/10.1001/2013. jamapsychiatry. 55

Nowotny, K. M., Peterson, R. L., \& Boardman, J. D. (2015). Gendered contexts: Variation in suicidal ideation by female and male youth across US states. Journal of Health and Social Behavior, 56(1), 114-130.

Olson-Kennedy, J. (2016). Mental health disparities among transgender youth: Rethinking the role of professionals. Jama Pediatrics, 170(5), 423-424.

Olson-Kennedy, J., Okonta, V., Clark, L. F., \& Belzer, M. (2017). Physiologic response to gender-affirming hormones among transgender. The Journal of Adolescent Health, 62 (4), 397-401. https://doi.org/10.1016/j.jadohealth.2017.08.005

Oransky, M., Zacher Burke, E., \& Steever, J. (2019). An interdisciplinary model for meeting the mental health needs of transgender adolescents and young adults: The Mount Sinai Adolescent Health Center approach. Cognitive and Behavioral Practice, 26, 603-616. https://doi.org/10.1016/j.cbpra.2018.03.002

Pachankis, J. E., Hatzenbuehler, M. L., Rendina, H. J., Safren, S. A., \& Parsons, J. T. (2015). LGB-affirmative cognitive-behavioral therapy for young adult gay and bisexual men: A randomized controlled trial of a transdiagnostic minority stress approach. Journal of Consulting and Clinical Psychology, 83, 875-889. https://doi.org/ $10.1037 / \operatorname{ccp} 0000037$

Pachankis, J. E., Williams, S. L., Behari, K., Job, S., McConocha, E. M., \& Chaudoir, S. R. (2020). Brief online interventions for LGBTQ young adult mental and behavioral health: A randomized controlled trial in a high-stigma, low-resource context. Journal of Consulting and Clinical Psychology, 88(5), 429. https://doi.org/10.1037/ cсp0000497

Park, S. (2015). Brief report: Sex differences in suicide rates and suicide methods among adolescents in South Korea, Japan, Finland, and the US. Journal of Adolescence, 40 74-77.

Pepping, C. A., Lyons, A., McNair, R., Kirby, J. N., Petrocchi, N., \& Gilbert, P. (2017) A tailored compassion-focused therapy program for sexual minority young adults with depressive symotomatology: Study protocol for a randomized controlled trial. BMC Psychology, 5(1), 1-7. https://doi.org/10.1186/s40359-017-0175-2

Perez-Brumer, A., Day, J. K., Russell, S. T., \& Hatzenbuehler, M. L. (2017). Prevalence and correlates of suicidal ideation among transgender youth in California: Finding from a representative, population-based sample of high school students. Journal of the American Academy of Child \& Adolescent Psychiatry, 56, 739-746. https://doi.org/ 10.1016/j.jaac.2017.06.010

Peters, J. R., Mereish, E. H., Krek, M. A., Chuong, A., Ranney, M. L., Solomon, J., Yen, S. (2019). Sexual orientation differences in non-suicidal self-injury, suicidality, and psychosocial factors among an inpatient psychiatric sample of adolescents. Psychiatry Research, 112664. https://doi.org/10.1016/j.psychres.2019.112664

Peterson, C. M., Matthews, A., Copps-Smith, E., \& Conard, L. A. (2017). Suicidality, selfharm, and body dissatisfaction in transgender adolescents and emerging adults with gender dysphoria. Suicide and Life-Threatening Behavior, 47(4), 475-482. https://doi. org/10.1111/sltb.12289

PFLAG. (2019, July). PFLAG National Glossary of Terms. PFLAG. https://pflag.org/g lossary.

Pitoňák, M. (2017). Mental health in non-heterosexuals: Minority stress theory and related explanation frameworks review. Mental Health and Prevention, 5, 63-73. https://doi.org/10.1016/j.mhp.2016.10.002

Plöderl, M., Sellmeier, M., Fartacek, C., Pichler, E.-M., Fartacek, R., \& Kralovec, K. (2014). Explaining the suicide risk of sexual minority individuals by contrasting the minority stress model with suicide models. Archives of Sexual Behavior, 43(8), 1559-1570. https://doi.org/10.1007/s10508-014-0268-4

Pompili, M., Lester, D., Forte, A., Seretti, M. E., Erbuto, D., Lamis, D. A., ... Girardi, P. (2014). Bisexuality and suicide: A systematic review of the current literature. The Journal of Sexual Medicine, 11(8), 1903-1913. https://doi.org/10.1111/jsm.12581

Preves, S. E. (2000). Negotiating the constraints of gender binarism: Intersexuals' challenge to gender categorization. Current Sociology, 48(3), 27-50.

Puckett, J. A., Horne, S. G., Surace, F., Carter, A., Noffsinger-Frazier, N., Shulman, J., Detrie, P., Ervin, A., \& Mosher, C. (2017). Predictors of sexual minority youth's reported suicide attempts and mental health. Journal of Homosexuality, 64. doi: https://doi.org/10.1080/00918369.2016.1196999.

Ream, G. L. (2019). What's unique about lesbian, gay, bisexual, and transgender (LGBT) youth and young adult suicides? Findings from the National Violent Death Reporting System. Journal of Adolescent Health, 64, 602-607. https://doi.org/10.1016/j. jadohealth.2018.10.303

Restifo, K., \& Bögels, S. (2009). Family processes in the development of youth depression: Translating the evidence to treatment. Clinical Psychology Review, 29(4), 294-316. https://doi.org/10.1016/j.cpr.2009.02.005
Rimes, K. A., Shivakumar, S., Ussher, G., Baker, D., Rahman, Q., \& West, E. (2018). Psychosocial factors associated with suicide attempts, ideation, and future risk in lesbian, gay, and bisexual youth. Crisis. doi.org/10.1027/0227-5910/a000527.

Robinson, B. E., Walters, L. H., \& Skeen, P. (1989). Response of parents to learning that their child is homosexual and concern over AIDS: A national study. Journal of Homosexuality, 18(1-2), 59-80.

Russell, S. T., \& Toomey, R. B. (2013). Risk and protective factors for suicidal thoughts among sexual minority youth: Evidence from the Add Health study. Journal of Gay \& Lesbian Mental Health, 17(2), 132-149.

Russon, J. \& Holubec N. (2019). Attachment-based family therapy for transgender youth. Seminar presented at American Association for Marriage and Family Therapy Annual Conference, Austin, TX.

Russon, J., Morrisey, J., Dellinger, J., Jin, B. \& Diamond, G. (2019). Implementing attachment-based family therapy for depressed and suicidal LGBTQ+ youth in community settings: Feasibility, Acceptability and Preliminary Effectiveness. Manuscript under review.

Ryan, C. (2009). Supporting families, healthy children: Helping families with lesbian, gay, bisexual, \& transgender children. San Francisco, CA: Family Acceptance Project.

Ryan, C. (2014). Generating a revolution in prevention, wellness \& care for LGBT children \& youth. Temple Political \& Civil Rights Law Review, 23(2), 331-344.

Savin-Williams, R. C. (1989). Parental influences on the self-esteem of gay and lesbian youths: A reflected appraisals model. Journal of Homosexuality, 17, 93-109. https:// doi.org/10.1300/J082v17n01 04

Savin-Williams, R. C. (1994). Verbal and physical abuse as stressors in the lives of lesbian, gay male, and bisexual youths: Associations with school problems, running away, substance abuse, prostitution, and suicide. Journal of Consulting and Clinical Psychology, 62, 261-269. https://doi.org/10.1037/0022-006X.62.2.261

Shankle, M. (2013). The handbook of lesbian, gay, bisexual, and transgender public health: A practitioner's guide to service. Routledge.

Sharaf, A. Y., Thompson, E. A., \& Walsh, E. (2009). Protective effects of self-esteem and family support on suicide risk behaviors among at-risk adolescents. Journal of Child and Adolescent Psychiatric Nursing, 22, 160-168. https://doi.org/10.1111/j.17446171.2009.00194.

Shearer, A., Herres, J., Kodish, T., Squitieri, H., James, K., Russon, J., ... Diamond, G. S. (2016). Differences in mental health symptoms across lesbian, gay, bisexual, and questioning youth in primary care settings. Journal of Adolescent Health, 59, 38-43. https://doi.org/10.1016/j.jadohealth.2016.02.005

Sheinfil, A. Z., Foley, J. D., Ramos, J., Antshel, K. M., \& Woolf-King, S. E. (2019). Psychotherapeutic depression interventions adapted for sexual and gender minority youth: A systematic review of an emerging literature. Journal of Gay \& Lesbian Mental Health, 23(4), 380-411. doi.org/10.1080/19359705.2019.1622616.

Shipherd, J. C., Green, K. E., \& Abramovitz, S. (2010). Transgender clients: Identifying and minimizing barriers to mental health treatment. Journal of Gay \& Lesbian Mental Health, 14, 94-108. https://doi.org/10.1080/19359701003622875

Simons, L., Schrager, S. M., Clark, L. F., Belzer, M., \& Olson, J. (2013). Parental support and mental health among transgender adolescents. Journal of Adolescent Health, 53 (6), 791-793. https://doi.org/10.1016/j.jadohealth.2013.07.019

Singh, A., \& Dickey, L. (Eds.). (2017). Perspectives on sexual orientation and diversity. Affirmative counseling and psychological practice with transgender and gender nonconforming clients. American Psychological Association. doi:https://doi.org/ $10.1037 / 14957-000$.

Smith, L. C., Shin, R. Q., \& Officer, L. M. (2012). Moving counseling forward on LGB and transgender issues: Speaking queerly on discourses and microaggressions. The Counseling Psychologist, 40(3), 385-408.

Smith, N. G., Hart, T. A., Kidwai, A., Vernon, J. R. G., Blais, M., \& Adam, B. (2017) Results of a pilot study to ameliorate psychological and behavioral outcomes of minority stress among young gay and bisexual men. Behavior Therapy, 48, 664-677. https://doi.org/10.1016/j.beth.2017.03.005

Smithee, L. C., Sumner, B. W., \& Bean, R. A. (2019). Non-suicidal self-injury among sexual minority youth: An etiological and treatment overview. Children and Youth Services Review, 96, 212-219, https://doi.org/10.1016/j.childyouth.2018.11.055

Spirito, A., Boergers, J., Donaldson, D., Bishop, D., \& Lewander, W. (2002). An intervention trial to improve adherence to community treatment by adolescents after a suicide attempt. Journal of the American Academy of Child \& Adolescent Psychiatry, 41(4), 435-442. https://doi.org/10.1097/00004583-200204000-00016

Staples, J. M., Neilson, E. C., Bryan, A. E. B., \& George, W. H. (2017). The role of distal minority stress and internalized transnegativity in suicidal ideation and nonsuicidal self-injury among transgender adults. The Journal of Sex Research, 55, 591-603. https://doi.org/10.1080/00224499.2017.1393651

Steensma, T. D., Biemond, R., de Boer, F., \& Cohen-Kettenis, P. T. (2011). Desisting and persisting gender dysphoria after childhood: A qualitative follow-up study. Clinical Child Psychology and Psychiatry, 16, 499-516. https://doi.org/10.1177/ 1359104510378303

Sticca, F., \& Perren, S. (2012). Is cyberbullying worse than traditional bullying? Examining the differential roles of medium, publicity, and anonymity for the perceived severity of bullying. Journal of Youth and Adolescence, 42, 739-750. https://doi.org/10.1007/s10964-012-9867-3

Taliaferro, L. A., \& Muehlenkamp, J. J. (2017). Nonsuicidal self-injury and suicidality among sexual minority youth: Risk factors and protective connectedness factors. Academic Pediatrics, 17(7), 715-722. https://doi.org/10.1016/j.acap.2016.11.002

Tebbe, E. A., \& Moradi, B. (2016). Suicide risk in trans populations: An application of minority stress theory. Journal of Counseling Psychology, 63(5), 520-533. https://doi. org/10.1037/cou0000152

Testa, R. J., Michaels, M. S., Bliss, W., Rogers, M. L., Balsam, K. F., \& Joiner, T. (2017). Suicidal ideation in transgender people: Gender minority stress and interpersonal 
theory factors. Journal of Abnormal Psychology, 126(1), 125-136. https://doi.org $10.1037 /$ abn0000234.

Thoma, B. C., Salk, R. H., Choukas-Bradley, S., Goldstein, T. R., Levine, M. D., \& Marshal, M. P. (2019). Suicidality disparities between transgender and cisgender adolescents. Pediatrics, 144. https://doi.org/10.1542/peds.2019-1183

Tilsen, J. B. (2013). Therapeutic conversations with queer youth: Transcending homonormativity and constructing preferred identities. Jason Aronson.

Toomey, R. B., Syvertsen, A. K., \& Flores, M. (2018). Are developmental assets protective against suicidal behavior? Differential associations by sexual orientation. Journal of Youth and Adolescence, 48, 788-801. https://doi.org/10.1007/s10964-018-0954-y

Valentine, S. E., \& Shipherd, J. C. (2018). A systematic review of social stress and menta health among transgender and gender non-conforming people in the United States. Clinical Psychological Review, 66, 24-38. https://doi.org/10.1016/j.cpr.2018.03.003

Van Orden, K. A., Witte, T. K., Cukrowicz, K. C., Braithwaite, S. R., Selby, E. A., \& Joiner, T. E., Jr. (2010). The interpersonal theory of suicide. Psychological Review, 117(2), 575-600. https://doi.org/10.1037/a0018697

Watt, S. O., Tskhay, K. O., \& Rule, N. O. (2018). Masculine voices predict well-being in female-to-male transgender individuals. Archives of Sexual Behavior, 47(4), 963-972. https://doi.org/10.1007/s10508-017-1095-1
Wilchins, R. (2004). Queer theory, gender theory: An instant primer. Alyson Books. World Professional Association for Transgender Health (2018). Standards of care for the health of transsexual, transgender, and gender nonconforming people (7th ed.). https://www.wpath.org/media/cms/Documents/SOC\%20v7/SOC\%20V7_English. pdf.

World Health Organization. (2019, Sept 2nd). Suicide. World Health Organization. https://www.who.int/news-room/fact-sheets/detail/suicide.

Yadegarfard, M., Meinhold-Bergmann, M. E., \& Ho, R. (2014). Family rejection, social isolation, and loneliness as predictors of negative health outcomes (depression, suicidal ideation, and sexual risk behavior) among Thai male-to-female transgender adolescents. Journal of LGBT Youth, 11, 347-363. https://doi.org/10.1080/ 19361653.2014 .910483

Yıldız, E. (2018). Suicide in sexual minority populations: A systematic review of evidence-based studies. Archives of Psychiatric Nursing, 32, 650-659. https://doi.org/ 10.1016/j.apnu.2018.03.003

Yüksel, S., Aslantaş Ertekin, B., Öztürk, M., Bikmaz, P. S., \& Oğlağu, Z. (2017) A clinically neglected topic: Risk of suicide in transgender individuals. Noro Psikiyatri Arsivi, 54, 28-32. https://doi.org/10.5152/npa.2016.1007 